\title{
Reversed-Phase Liquid Chromatography In-Line with Negative Ionization Electrospray Mass Spectrometry for the Characterization of the Disulfide-Linkages of an Immunoglobulin Gamma Antibody
}

\author{
Dirk Chelius, Mary E. Huff Wimer, and Pavel V. Bondarenko \\ Amgen Inc., Thousand Oaks, California, USA
}

\begin{abstract}
In this report, we present a new approach for the determination of the disulfide bond connectivity in proteins using negative ionization mass spectrometry of nonreduced enzymatic digests. The mass spectrometric analysis in negative ion mode was optimized to allow in-line analysis coupled directly to the HPLC system used for the separation of the peptides resulting from enzymatic digestion. We determined the disulfide structure of a human immunoglobulin gamma 2 (IgG2) antibody containing 18 unique cysteine residues linked via 11 unique disulfide bonds. The efficiency of the gas-phase dissociation of disulfide-linked peptides using negative electrospray ionization was evaluated for an ion trap mass spectrometer and an orthogonal acceleration time-of-flight mass spectrometer. Both mass spectrometry techniques provided efficient in-source fragmentation for the identification of the disulfide-linked peptides of the antibody. Both instruments were limited in the number of disulfide bonds that could be dissociated. Seven of the 11 unique disulfide linkages have been determined, including the linkage of the light chain to the heavy chain. Only the disulfide connectivity of the hinge peptide $\mathrm{H} 6 \mathrm{H} 7 \mathrm{H} 8 \mathrm{H} 9\left(\mathrm{C}^{6} \mathrm{C}^{7} \mathrm{VEC}^{8} \mathrm{PPC}^{9} \mathrm{PAPPVAGPSVFLFPPKPK}\right)$ could not be determined (numbering the cysteine residues sequentially from the N-terminus and labeling the heavy chain cysteines " $\mathrm{H}$ " and the light chain cysteines "L"). However, we identified the

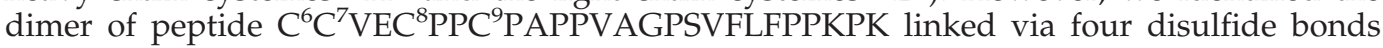
based on the unique molecular weight of this dipeptide. The established linkages were H1 to $\mathrm{H} 2, \mathrm{H} 10$ to H11, H12 to H13, L1 to L2, L3 to L4, and L5 to H3H4. The intrachain linkages of the light chain (L1 to L2, L3 to L4), and heavy chain (H10 to H11, H12 to H13) domains were identical to the linkages found in IgG1 antibodies. (J Am Soc Mass Spectrom 2006, 17, 1590-1598) (C) 2006 American Society for Mass Spectrometry
\end{abstract}

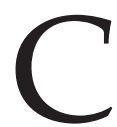
orrect disulfide bond formation is critical for the formation of the correct three-dimensional structure of a protein and for its biological function. Immunoglobulin gamma (IgG) antibodies are a widely used modality for biological pharmaceuticals because of their high specificities and long life in vivo. IgGs are composed of two identical heavy chains and two identical light chains connected via disulfide bonds (Figure 1). Peptide mapping in-line with mass spectrometry has become the method of choice for the determination of disulfide structures within proteins. However, very little has been reported about the disulfide structure of $\operatorname{IgG}$ molecules. The disulfide structure for an IgG1 has been solved by Mhatre et al. [1] using MALDI-TOF and ESI mass spectrometry. The structure of an IgG4 has been solved by Zhang et al. [2], and the disulfide

Published online August 14, 2006

Address reprint requests to Dr. D. Chelius, Amgen Inc., One Amgen Center Dr., B2-1-A, Thousand Oaks, CA 91320, USA. E-mail: dchelius@amgen.com structure of the hinge region of a mouse IgG2 molecule was solved by Yen et al. in 2002 [3]. Human IgG2 is unique in its disulfide structure in that the two halves of the molecule are linked via four cysteine residues on each heavy chain in the hinge region. In contrast, for example, IgG1, the most abundant antibody in circulation, is linked by two cysteine residues on each heavy chain. The identification of disulfide-linked peptides in IgG molecules is challenging because of their larger size and complexity of fragmentation mass spectra compared with single-chain peptides. Typically, reduction and alkylation in solution is performed on disulfide peptides to confirm their identity. This step takes extra time for sample preparation. Although gas-phase fragmentation of peptides and proteins using their positive ions has been actively studied and used in a number of applications, negative ions are less utilized, largely due to the relatively low intensity of these ions compared with the positive ions. Gas-phase reduction is an attractive practical alternative to the wet chemistry reduction 


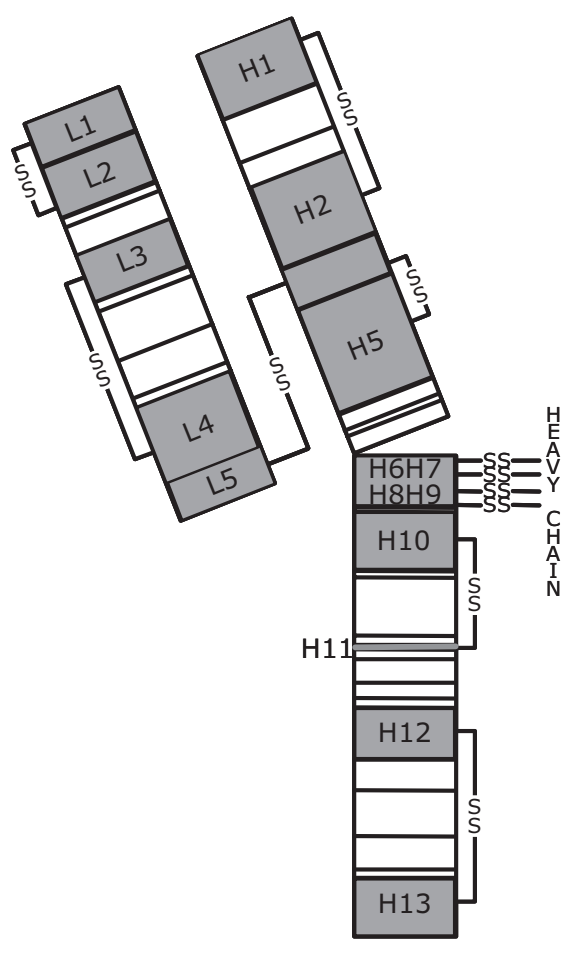

Figure 1. Schematic diagram of one of the two identical halves of an IgG2 antibody. The molecule is composed of two identical heavy chains and two identical light chains; only one of each is shown. Disulfide bonds are shown as "-SS-", and the predicted Lys- $C$ fragments are delineated with solid lines. The cysteinecontaining fragments generated by Lys-C digestion are numbered sequentially from the $\mathrm{N}$-termini and labeled " $\mathrm{H}$ " for heavy chain and " $\mathrm{L}$ " for light chain. For example, fragment L1 contains the first cysteine residue in the light chain, and fragment $\mathrm{H} 3 \mathrm{H} 4$ contains the third and forth cysteine residues in the heavy chain.

because no additional sample preparation steps are required. Selected cleavages at disulfide bond sites have been reported for positive ions formed through fast atom bombardment $[4,5]$ and MALDI [6-9]. Characterization of the disulfides of biothiols by electrospray ionization and triple-quadrupole tandem mass spectrometry was also reported before [10]. In 1988, negative-ion thermospray mass spectrometry was employed for the analysis of glutathione conjugates [11]. Utilizing negative-ion reduction, the disulfide-linked peptides undergo extensive fragmentation, which occurs primarily at the sulfur-sulfur bonds. McLuckey and coworkers showed dissociation of disulfide-linked gaseous polypeptide/protein anions using direct infusion of proteins at high $\mathrm{pH}$ and collision-induced dissociation [12]. The reduction of disulfide-containing peptides anions in the gas phase has been utilized for peptide mapping of several proteins containing disulfide bonds also using collision-induced dissociation [13]. The current study describes an application of negative ion electrospray ionization mass spectrometry (ESI MS) for the identification of disulfide-linked peptides of a recombinant human IgG2 antibody. We evaluated this technique in-line with reversed-phase HPLC using $0.1 \%$ trifluoroacetic acid solutions ( $\mathrm{pH} 2)$ employing commercially available electrospray ionization ion trap (ESI-IT) and orthogonal acceleration time of flight (ESI-TOF) mass spectrometry without additional modifications.

\section{Experimental}

\section{Materials and Methods}

The recombinant human monoclonal IgG2 antibody analyzed in this study was expressed and purified at Amgen using standard manufacturing techniques.

\section{Endopeptidase Lys-C Digestion}

The IgG2 was denatured at $13 \mathrm{mg} / \mathrm{mL}$ in $6.5 \mathrm{M}$ guanidinium chloride $(\mathrm{GdmCl}), 40 \mathrm{mM}$ sodium phosphate $\mathrm{pH}$ 7.0. Iodoacetamide $(0.6 \mathrm{mM})$ was added to alkylate any free thiol groups that could have complicated the analysis. The IgG2 solution $(60 \mu \mathrm{L})$ was mixed with 680 $\mu \mathrm{L}$ of a digestion buffer containing $4 \mathrm{M}$ urea, $20 \mathrm{mM}$ hydroxylamine hydrochloride, and $100 \mathrm{mM}$ sodium phosphate $\mathrm{pH} 7.0$ to yield a $1 \mathrm{mg} / \mathrm{mL}$ IgG2 solution containing $3.5 \mathrm{M}$ urea, $0.5 \mathrm{M} \mathrm{GdmCl}, 17.4 \mathrm{mM}$ hydroxylamine hydrochloride, and $90 \mathrm{mM}$ sodium phosphate at pH 7.0. Endopeptidase Lys-C (Lys-C; Wako Chemicals USA, Richmond, VA) was added at a ratio of 1:20 enzyme to substrate, the solution was overlaid with $\mathrm{N}_{2}$, and the samples were incubated at $37^{\circ} \mathrm{C}$ for $20 \mathrm{~h}$. After incubation, the samples $(125 \mu \mathrm{L})$ were quenched with $25 \mu \mathrm{L}$ aliquots of $5 \%$ trifluoroacetic acid (TFA; Pierce, Rockford, IL).

\section{HPLC Separation of Lyc-C Peptides}

The nonreduced peptides were separated by reversedphase HPLC using an Agilent 1100 HPLC equipped with a diode-array detector, autosampler, microflow cell, and temperature controlled column compartment (Agilent, Palo Alto, CA). The column was heated at $50{ }^{\circ} \mathrm{C}$ to enhance separation. The solvents were A: $0.1 \%$ trifluoroacetic acid (TFA; Pierce, Rockford, IL) in water, and B: $0.089 \%$ TFA in 90\% acetonitrile (Baker, Phillipsburg, NJ) in water. Separation was performed on a Jupiter C5 column packed with $5 \mu \mathrm{m}$ particles, $300 \AA$ pore size (Phenomenex, Torrance, CA). The column was initially equilibrated at $2 \%$ Solvent B. Two min after sample injection, the concentration of mobile phase B was increased to $22 \%$ over $38 \mathrm{~min}$ followed by an increase to $45 \%$ over $100 \mathrm{~min}$. The column was reequilibrated by ramping up mobile phase B to $100 \%$ over $5 \mathrm{~min}$, holding for $5 \mathrm{~min}$ at $100 \% \mathrm{~B}$, dropping down to $2 \%$ B over 5 min followed by $15 \mathrm{~min}$ at $2 \%$ B. UV absorption was monitored at 214 and $280 \mathrm{~nm}$.

The same method was used in-line with both mass spectrometers (ESI-IT and ESI-TOF) with the following minor modifications: the column size was $250 \times 2.0 \mathrm{~mm}$ using a flow rate of $200 \mu \mathrm{L} / \mathrm{min}$ for the ESI-IT and 150 $\times 1.0 \mathrm{~mm}$ using a flow rate of $50 \mu \mathrm{L} / \mathrm{min}$ for the 
Table 1. Cysteine-containing peptides from a nonreduced Lys-C digestion of a recombinant IgG2 observed using positive- and negative-ion mode ${ }^{a}$

\begin{tabular}{|c|c|c|c|c|c|}
\hline Peptides & Elution time & Obs. mass (ion trap) & Obs. mass (TOF) & Calc. mass ave. ${ }^{\mathrm{b}}$ & Calc. mass mono. ${ }^{b}$ \\
\hline L1-SS-L2 & 103 & 11386.0 & $11386.5^{\mathrm{c}}$ & 11386.5 & 11379.5 \\
\hline L3-SS-L4 & 79 & 3886.8 & 3884.0 & 3886.5 & 3883.9 \\
\hline L5-SS-H3H4-SS-H5 & 112 & 10095.6 & $10097.0^{c}$ & 10096.3 & 10089.8 \\
\hline H1-SS-H2 & 107 & 9553.6 & $9550.2^{c}$ & 9550.8 & 9544.7 \\
\hline H6H7H8H9-SS-H6H7H8H9 & 102 & 5355.0 & 5354.2 & 5354.6 & 5350.6 \\
\hline H10-SS-H11 & 89 & 4807.8 & 4803.4 & 4806.3 & 4803.3 \\
\hline H12-SS-H13 & 68 & 4091.0 & 4088.2 & 4090.6 & 4088.0 \\
\hline L1 & 103 & 4358.8 & 4355.2 & 4357.8 & 4355.2 \\
\hline L2 & 103 & 7026.4 & $7028.5^{c}$ & 7030.7 & 7026.3 \\
\hline L3 & 79 & 2070.0 & 2068.0 & 2069.4 & 2068.0 \\
\hline L4 & 79 & 1820.3 & 1817.9 & 1819.1 & 1817.9 \\
\hline L5 & 112 & - & 811.3 & 811.9 & 811.3 \\
\hline $\mathrm{H} 1$ & 107 & 4498.6 & 4494.2 & 4497.1 & 4494.3 \\
\hline $\mathrm{H} 2$ & 107 & 5056.6 & 5052.6 & 5055.7 & 5052.4 \\
\hline H3H4 & 112 & - & - & 2579.0 & 2577.3 \\
\hline H5 & 112 & - & - & 6709.4 & 6705.2 \\
\hline H6H7H8H9 & 102 & - & - & 2681.3 & 2679.3 \\
\hline $\mathrm{H} 10$ & 89 & 4558.4 & 4556.2 & 4559.0 & 4556.2 \\
\hline H11 & 89 & - & - & 249.3 & 249.1 \\
\hline $\mathrm{H} 12$ & 68 & 1103.8 & 1103.6 & 1104.3 & 1103.6 \\
\hline $\mathrm{H} 13$ & 68 & 2987.7 & 2986.5 & 2988.3 & 2986.4 \\
\hline
\end{tabular}

Although ions were observed in a variety of multiple-charge states, all measured $\mathrm{m} / \mathrm{z}$ values are given as molecular masses of the neutral state. Fragment ions in negative ion mode are heterogeneous resulting from two species that differ in mass by $2 \mathrm{Da}$, because of the transferred hydrogen atoms [12]. Although those two species were resolved with the ESI-TOF instrument, only the species with the hydrogen atoms are shown for simplification.

a Observed masses are compared with calculated masses based on the peptide sequences. The observed masses are close to average masses for the ion trap data and monoisotopic for ESI-TOF.

${ }^{b}$ For the calculated masses of the non-disulfide-linked peptides, the side chain of cysteine residue was $-\mathrm{CH}_{2}-\mathrm{SH}_{\text {. }}$

${ }^{\mathrm{c}}$ The isotopes were not resolved for this peak.

ESI-TOF. $50 \mu \mathrm{g}$ of the nonreduced Lys-C digested sample was injected onto the column for mass spectrometry analysis using the ESI-IT and $10 \mu \mathrm{g}$ of the nonreduced sample was injected onto the column for analysis using the ESI-TOF.

\section{Mass Spectrometry Analysis of Lyc-C Peptides}

The HPLC was directly coupled to a Finnigan LCQ Deca ion trap mass spectrometer (Thermo Electron, San Jose, CA) or an LCT ESI-TOF (Waters, Milford, MA) mass spectrometer. The ESI voltage was $4.5 \mathrm{kV}$ in positive ion mode and $-3.0 \mathrm{kV}$ in negative-ion mode. The capillary temperature was $250^{\circ} \mathrm{C}$. The fragmentation in positive mode was obtained using ion trap collision energies of $35 \%$. Each full-scan mass spectrum was followed by a data-dependent MS/MS scan of the most intense ion. The instrument was calibrated to higher mass range $(4000 \mathrm{Da})$ and tuned by infusion of insulin (Sigma, St Louis, MO). Fragmentation in negative mode was optimized using direct infusion of insulin with monitoring of the intensity of the fragment ion at 1681.6 Da. The tube lens behind the heated capillary was set to maximum value of $-100 \mathrm{~V}$ to achieve optimal fragmentation in the nozzle-skimmer region.

The spray voltage of the ESI-TOF mass spectrometer was set at $2.6 \mathrm{kV}$ in positive and $-2.0 \mathrm{kV}$ in negative ionization mode. The instrument was internally calibrated using internal calibration ions of known peptides in the ion chromatogram. Fragmentation of disulfide-containing peptides in negative ionization mode was optimized by direct infusion of insulin and monitoring the fragment ion at $m / z 1681.6 \mathrm{Da}$. The ion gauge voltage 1 was set to a maximum value of $200 \mathrm{~V}$ for optimal fragmentation in the region between the atmosphere-vacuum interface and the stacked ring ion guide.

Using ion trap data, peptides were identified automatically by software developed in-house which correlated the experimental tandem mass spectra against theoretical tandem mass spectra generated from the known antibody amino acid sequence for peptide identification [14, 15]. All disulfide-linked peptides were identified manually using accurate mass information from both ESI-IT and ESI-TOF.

\section{Results and Discussion}

Endopeptidase Lys-C digestion was used to generate disulfide-linked peptides from a recombinant IgG2 molecule. The predicted Lys-C peptides containing cysteine residues are illustrated in Table 1 (the nomenclature is based on numbering the cysteine residues from the N-termini of heavy " $\mathrm{H}$ " and light " $\mathrm{L}$ " chains). The fragments were separated by the $C 5$ reversed-phase 


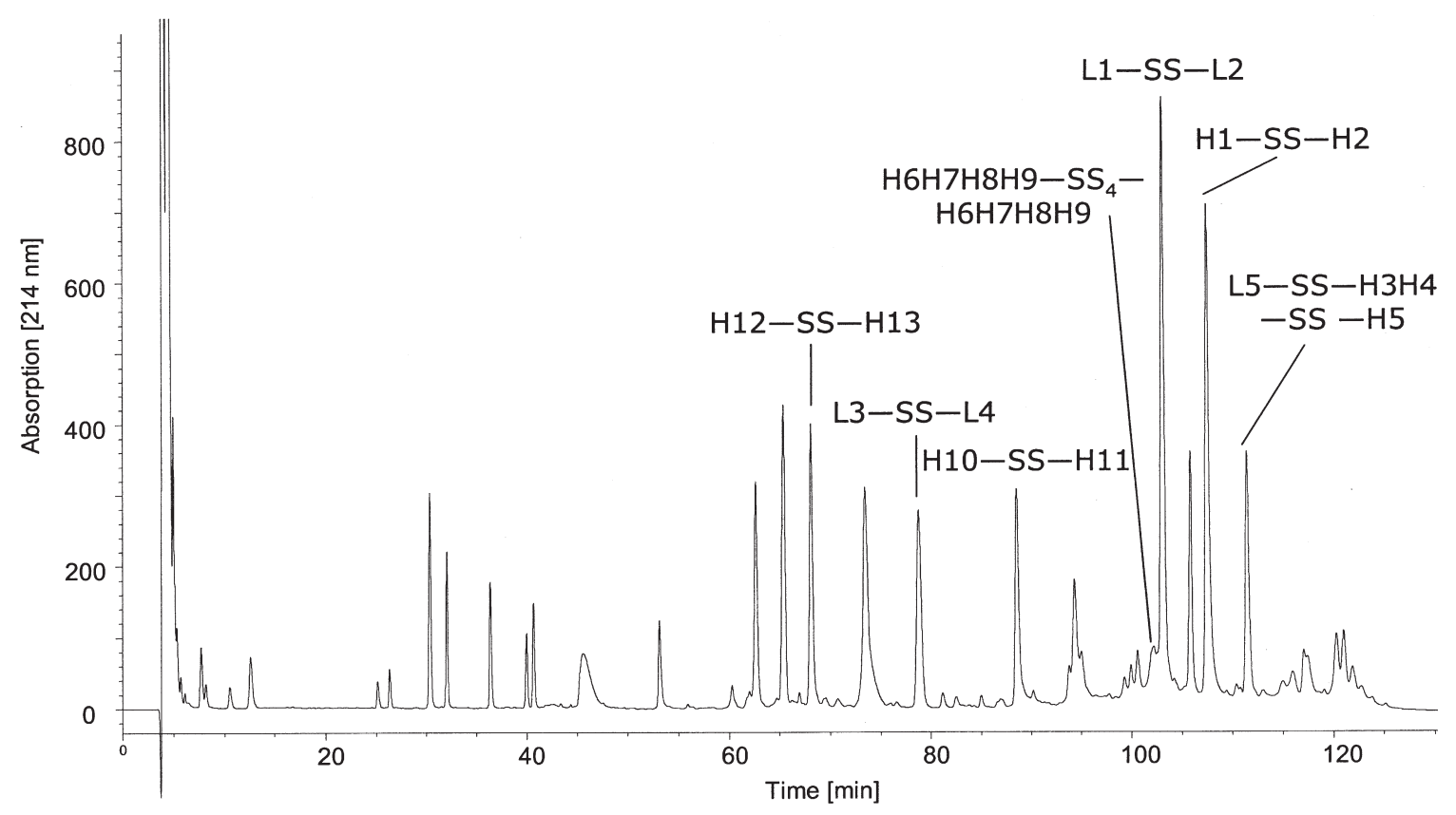

Figure 2. Reversed-phase chromatogram with UV absorbance at $214 \mathrm{~nm}$ of a Lyc-C digest of a non-reduced IgG2 molecule. Recombinant IgG2 $(40 \mu \mathrm{g})$ was digested with Lys-C and applied to a C5 reversed-phase HPLC column using a gradient of acetonitrile in $0.1 \%$ aqueous TFA as described in the methods. The peaks indicative of disulfide-linked peptides are labeled as described in Figure 1. The HPLC was directly coupled to an ESI mass spectrometer.

HPLC column using a gradient of acetonitrile with $0.1 \%$ TFA. The UV chromatogram of the Lys-C digested recombinant IgG2 is shown in Figure 2, and the disulfide-linked peptides are labeled. All nondisulfide containing peptides larger than two amino acids could be identified from the positive ionization mass spectra using fully automated software as described above. Fragments containing all 18 unique cysteine residues (13 from the heavy chain and five from the light chain) were identified in the HPLC fractions by their molecular masses and with the use of the unique fragmentation in negative ionization mode. The detected peptides accounted for more than $90 \%$ of the total amino acids of the IgG2 molecule. The observed and calculated molecular weights for the various cysteine-containing peptides are listed in Table 1 and are discussed in more detail below.

We modified the negative ion electrospray conditions originally described by Chrisman and McLuckey [12] by using the mass spectrometers in-line with the reversed-phase liquid chromatography. Fragmentation of disulfide-linked peptides was achieved using negative ionization in the low-pH mobile phase typically used for reversed-phase LC. This allowed the direct coupling of the LC system to the mass spectrometer. Changing the $\mathrm{pH}$ after the column and before the mass spectrometer from a $\mathrm{pH} 2.5$ to around 11 by infusing ammonia hydroxide solution was performed (data not shown), but did not improve the intensity of the signal nor did it improve the amount of disulfide dissociation. Higher $\mathrm{pH}$ also did not affect the charge state of the ions observed in negative ion mode, e.g., the charge state did not increase at higher $\mathrm{pH}$ (data not shown).

Figure 3 shows the ion trap full mass spectra of peptides H12-SS-H13 linked via one disulfide bond in the positive (Figure $3 a$ ) and negative (Figure $3 b$ ) ionization mode. The intact dipeptide can be observed at $\mathrm{m} / \mathrm{z}$ $2046.5(2+)$ and $1365.0(3+)$ in positive ion mode, and at $\mathrm{m} / \mathrm{z} 2044.6(2-)$ in the negative ion mode. The differences between $m / z$ values for positive and negative ions $(2+$ and $2-$, for example) are caused by the fact that positive ions gain mass by adding protons and negative ions lose mass by losing protons. In-source fragmentation of the dipeptide in negative ion mode resulted in cleavage at the sulfur-sulfur bond yielding peptides $\mathrm{H} 12-\mathrm{S}^{-}$( $\mathrm{m} / \mathrm{z}$ 1102.8) and H13-S $\mathrm{S}^{-}$(m/z 2986.7). This fragmentation was specific to the negative ion mode and was not observed in the positive ion mode. The main peaks of this fragmentation were accompanied by signature ions of plus sulfur and minus sulfur atoms corresponding to cleavage at different sites within the carbon-sulfur-sulfur-carbon disulfide linkages [for H12 $\mathrm{m} / \mathrm{z} 1070.4(-\mathrm{S})$ and $\mathrm{m} / \mathrm{z} 1136.3(+\mathrm{S})$ and for H13 m/z $2954.3(-S)]$. Similar results were achieved with the ESI-TOF technique (Figure 3c, d). The ratio of parent ions $(\mathrm{m} / \mathrm{z} 2044)$ to fragment ions $(\mathrm{m} / \mathrm{z} 1102$ and 2986) was higher in the TOF instrument (Figure 3d) compared with the ion trap (Figure $3 b$ ) indicating that the insource dissociation of these disulfide-linked peptides was more efficient in the ion trap for this particular peptide. However, a major drawback of the ion trap was its limited mass range (400-4000 Da). We needed 

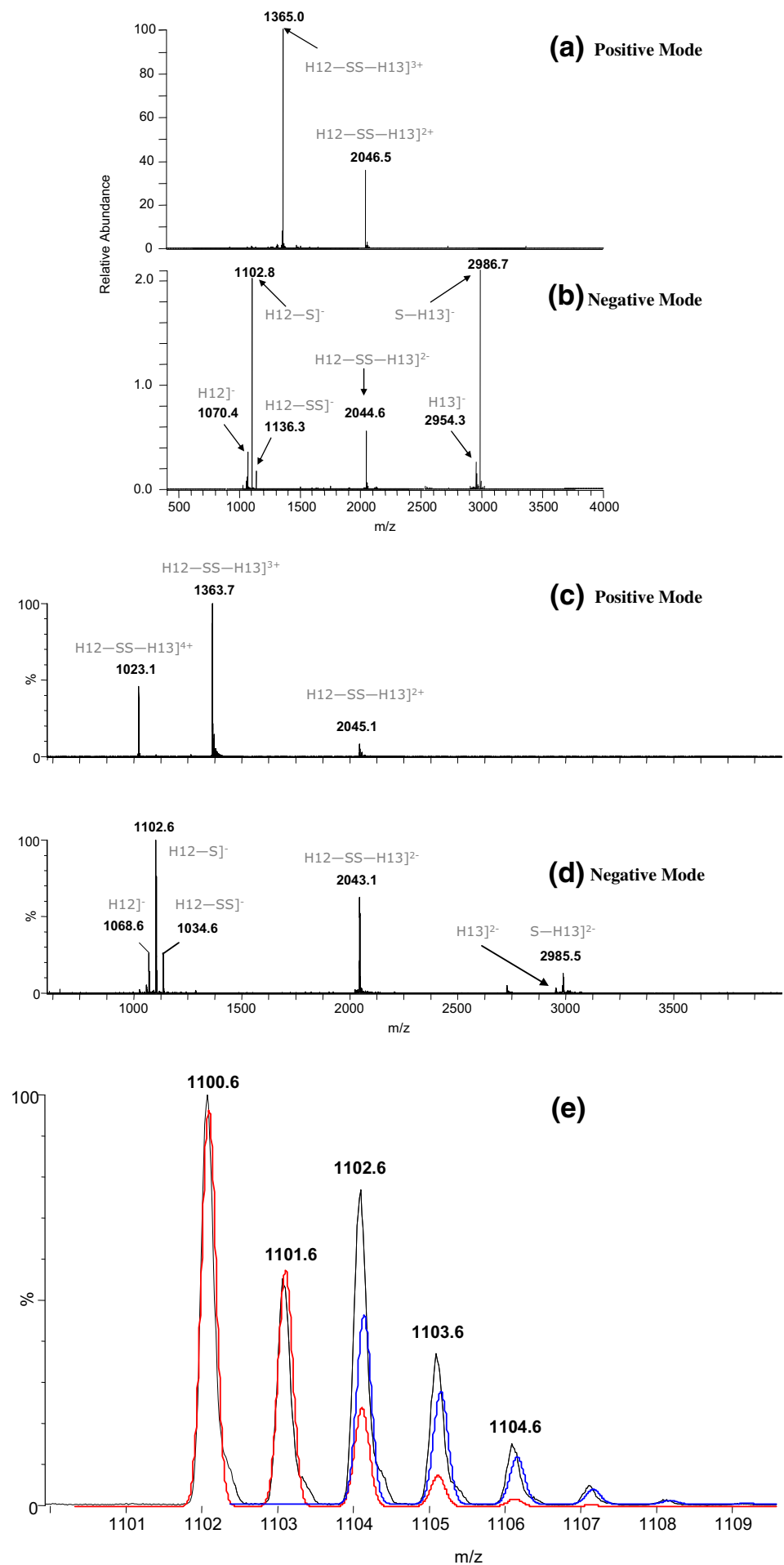

Figure 3. Mass spectra of the HPLC peak eluting at $68 \mathrm{~min}$ (see Figure 2). (a) Positive ESI-IT, (b) negative ESI-IT, (c) positive ESI-TOF, and (d) negative ESI-TOF. The HPLC peak was identified as two peptides from the heavy chain linked via disulfide bonds (H12-SS-H13). Fragment ions are heterogeneous differing in mass by $2 \mathrm{Da}$, which could be resolved on the ESI-TOF instrument. Only the ions of the larger fragments are labeled for simplicity. (e) A zoomed view of $\mathrm{H} 12-\mathrm{S}^{-}$ions from Figure $3 \mathrm{~d}$. The observed isotope distribution (black) and theoretical isotope distribution for ions with (blue) and without (red) hydrogen transfer as described by Chrisman and McLuckey [11]. Only the species with the hydrogen atoms (1102.8 Da) are labeled in Figure 3d. 

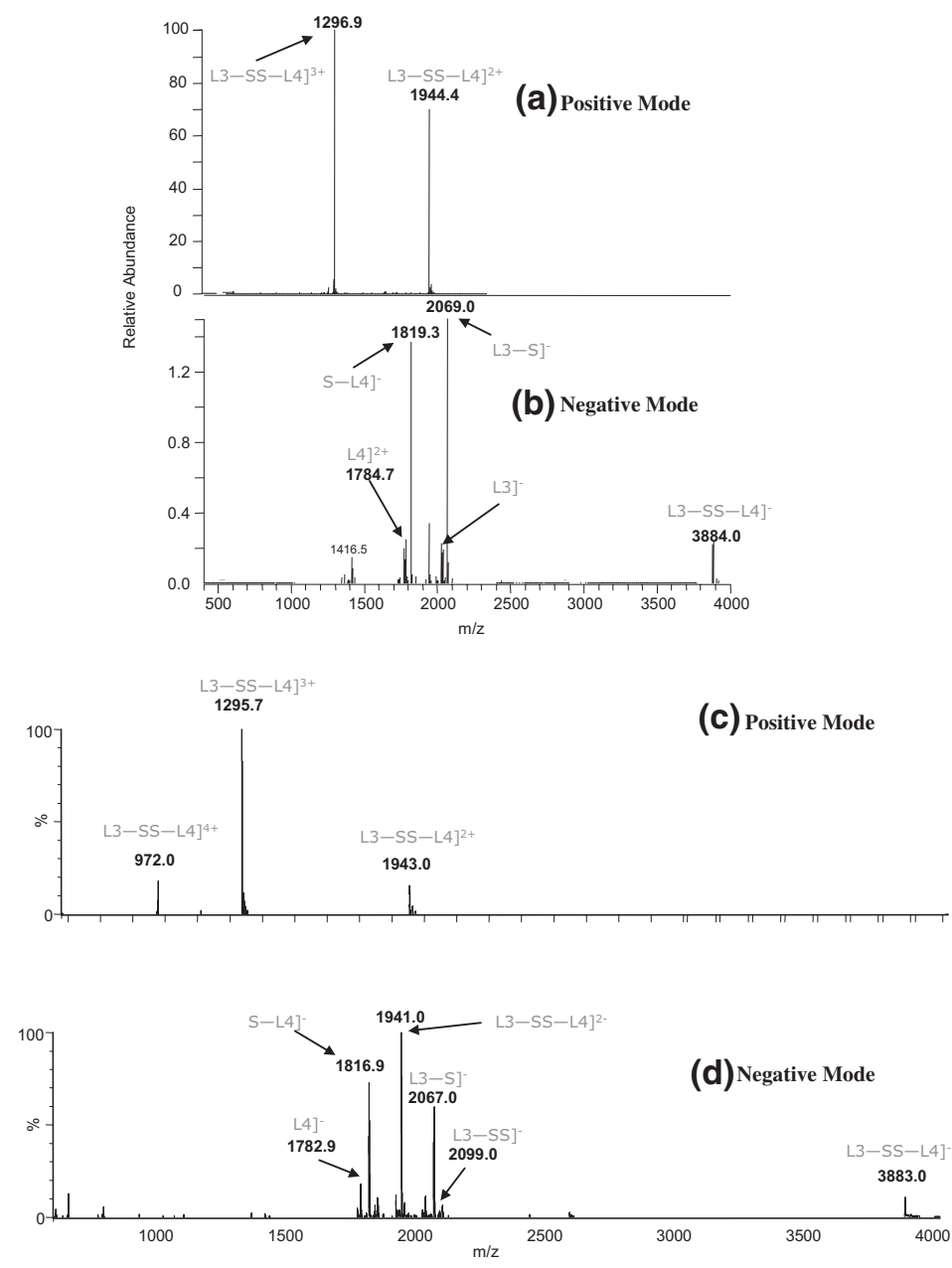

Figure 4. Mass spectra of HPLC peak eluting at 79 min (see Figure 2). (a) Positive ESI-IT, (b) negative ESI-IT, (c) positive ESI-TOF, and (d) negative ESI-TOF. The HPLC peak was identified as two peptides from the light chain linked via disulfide bonds (L3-SS-L4).

to extend the mass range to $\mathrm{m} / \mathrm{z} 4000$ from the typical upper limit of $\mathrm{m} / \mathrm{z} 2000$ because most ions in the negative ionization mode seem to populate singly or doubly charged states.

Additionally, the higher mass accuracy (10 ppm or better) and the higher resolution (5000 Da or better) of the ESI-TOF compared with the ion trap instrument are clear advantages of the former technique, which allowed positive identification without MS/MS data in most cases.

In-source fragmentation in negative ion mode rather than collision-induced dissociation in the ion trap was used for the dissociation of the disulfide-linked peptides in our study to increase ion intensity of the fragments. It is our understanding that the fragmentation of disulfide bonds in negative ion mode has similarities with the electron capture dissociation, where the fragmentation is caused by the low-energy electrons rather than due to collisional activation [16]. We observed that the collisional activation by the insource voltages enhanced to some extent the cleavage of disulfide bonds. However, it appeared that collision- induced fragmentation of selected ions in the ion trap or collision cell of an ESI-TOF instrument (MS/MS) are not needed to generate the disulfide fragmentation. For the ion trap instrument used in the experiments, the insource fragmentation of the chromatographically separated peptides had the advantage of much higher sensitivity compared with the MS/MS scan of selected ions. Also, the quality of the fragmentation achieved in-source was better in comparison with the fragmentation during collision-induced dissociation (MS/MS) based on the intensity and the signal to noise ratio (data not shown). The in-source fragmentation for the negative ionization mode was essential for the orthogonalTOF because our instrument (LCT) did not have MS/MS capabilities.

According to the data presented by Chrisman and McLuckey [12], the cleavages at the sulfur-sulfur and sulfur-carbon bonds are heterogeneous. When the cleavage occurs, so that one chain contains both sulfur atoms, hydrogen is transferred from the sulfur-less chain to create peptides with $>\mathrm{C}_{\alpha}=\mathrm{CH}_{2}$ and $>\mathrm{C}_{\alpha} \mathrm{H}-\mathrm{CH}_{2}-\mathrm{S}-\mathrm{SH}$ side chains. When the cleavage 
occurs between the sulfurs, one of the chains receives a hydrogen from the other chain to create peptides with $>\mathrm{C}_{\alpha} \mathrm{H}-\mathrm{CH}_{2}-\mathrm{SH}$ and $>\mathrm{C}_{\alpha} \mathrm{H}-\mathrm{CH}=\mathrm{S}$ side chains. These heterogeneous peaks due to hydrogen transfers were resolved in the ESI-TOF instrument. Figure 3e shows the observed ions of fragment H12-S. The isotope distribution clearly demonstrates the presence of two ions with $\mathrm{m} / \mathrm{z}$ values of 1100.6 and 1102.6 corresponding to the fragments with hydrogen and without hydrogen transfer. For simplicity, we labeled only the ions with the hydrogen atoms in Figure $3 \mathrm{~d}$ and in all following figures.

Figure 4 shows the ion trap full scan mass spectra of peptides L3-SS-L4 linked via one disulfide bond in the positive (Figure $4 a$ ) and negative (Figure $4 b$ ) ionization modes. The intact dipeptide was observed at $\mathrm{m} / \mathrm{z}$ $1944.4(2+)$ and $1296.9(3+)$ in positive ion mode, and at $\mathrm{m} / \mathrm{z} 3884.0(1-)$ and $1942.4(2-)$ in negative ion mode. In-source fragmentation of the dipeptide in negative ion mode resulted in cleavage at the sulfur-sulfur bond yielding peptides $\mathrm{L} 3-\mathrm{S}^{-}(\mathrm{m} / \mathrm{z} 2069.0)$ and $\mathrm{L} 4-\mathrm{S}^{-}(\mathrm{m} / \mathrm{z}$ 1819.3). This fragmentation was specific to the negative ion mode and was not observed in the positive ion mode. Similar results were achieved with the TOF technology (Figure 4c, d). Again, the ratio of parent ions $(\mathrm{m} / \mathrm{z} 1942)$ to fragment ions $(\mathrm{m} / \mathrm{z} 1819$ and 2069) was higher in the TOF (Figure 4d) compared with the ion trap (Figure $4 \mathrm{~b}$ ) confirming that the in-source dissociation of disulfide-linked peptides (Figures 3 and 4) was more efficient in the ion trap.

All other peptides analyzed in this study did not show a significant difference in the efficiency of insource dissociation. For simplicity, we show only the ESI-TOF mass spectra of the following peptides, since the mass accuracy and the resolution of those spectra are higher compared to the ion trap data. Figure 5 shows the ESI-TOF mass spectra of peptides
H10-SS-H11 linked via one disulfide bond in the positive (Figure 5a) and negative (Figure $5 b$ ) ionization modes. The intact dipeptide was observed at $\mathrm{m} / \mathrm{z} 2402.7$ $(2+), m / z 1602.1(3+)$, and $m / z 1201.9(4+)$ in positive ion mode, and at $\mathrm{m} / \mathrm{z} 2400.7$ (2-) in the negative ion mode. In-source fragmentation of the di-peptide in negative ion mode resulted in cleavage between the sulfur atoms yielding peptides $\mathrm{H} 10-\mathrm{S}^{2-}(\mathrm{m} / \mathrm{z} 2277.1)$, and the ions of \pm sulfur atom at $\mathrm{m} / \mathrm{z} 2260.1(2-)$ and $\mathrm{m} / \mathrm{z}$ $2293.1(2-)$. This fragmentation was specific to the negative ion mode and was not observed in the positive ion mode. The $\mathrm{H} 11-\mathrm{S}^{-}$ion (theoretical mass of 249.3 $\mathrm{Da}$ ) was not observed due to the mass range setting of $\mathrm{m} / \mathrm{z} 600$ to $6000 \mathrm{Da}$ used in the experiment. Similar results were achieved with the ion trap (data not shown). The intensity of the fragment ion in Figure 5 was much lower compared to the intensities observed for peptide shown in Figures 3 and 4. We expect the large size of peptide H10-SS-H11 of 4803.3 Da compared with the size of previously described peptides (3883.9 and $4088.0 \mathrm{Da}$ ) plays a role in the efficiency of the in-source fragmentation. In addition, we observed the formation of a dimer peak at $m / z 3201.9$ (3-), which could also be the cause of the limited fragmentation. Studies to limit the amount of dimer formation and its effect on the fragmentation efficiency are in progress.

The intact dipeptide L1-SS-L2 linked via one disulfide bond was observed at $\mathrm{m} / \mathrm{z} 2847.6(4+), \mathrm{m} / \mathrm{z}$ $2278.3(5+), m / z 1898.8(6+), m / z 1627.6(7+), m / z 1424.3$ $(8+)$, and $m / z 1266.2(9+)$ in positive ion mode, and at $\mathrm{m} / \mathrm{z} 5692.3(2-), \mathrm{m} / \mathrm{z} 3794.5(3-)$, and $\mathrm{m} / \mathrm{z} 2845.6(4-)$ in the negative ion mode (data not shown). In-source fragmentation of the di-peptide in negative ion mode resulted in cleavage at the sulfur atom yielding peptides L1- $\mathrm{S}^{2-}(\mathrm{m} / \mathrm{z} 2176.6)$ and L2- $\mathrm{S}^{2-}(\mathrm{m} / \mathrm{z}$ 3513.3) (data not shown). This fragmentation was specific to the negative ion mode and was not observed in the positive ion
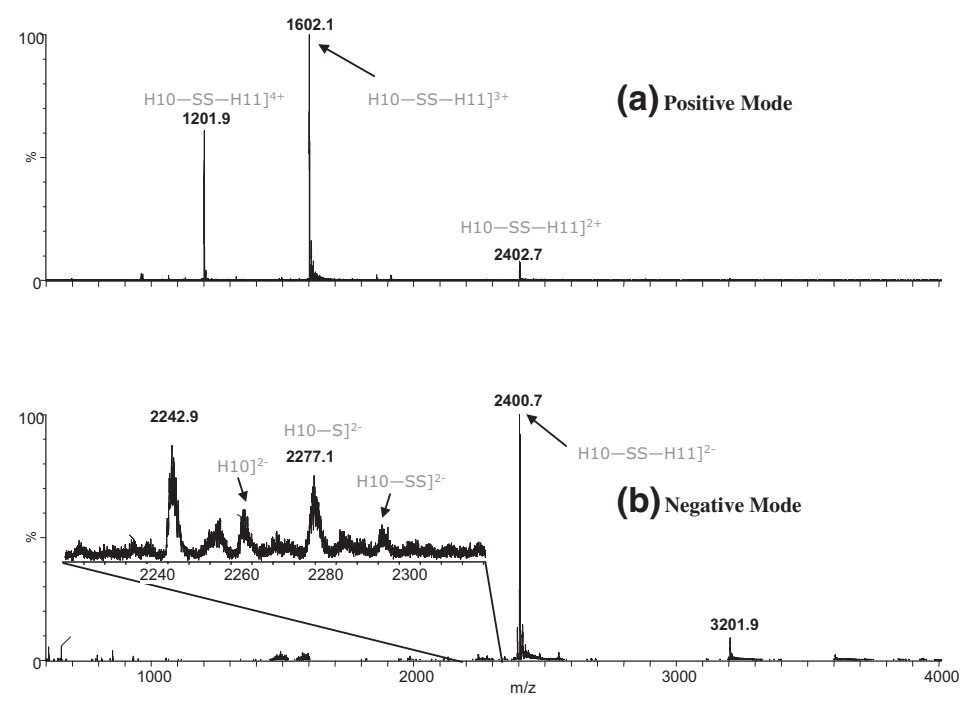

Figure 5. Mass spectra of HPLC peak eluting at $88 \mathrm{~min}$ (see Figure 2). (a) Positive ESI-TOF, (b) negative ESI-TOF. The HPLC peak was identified as two peptides from the heavy chain linked via disulfide bonds (H10-SS-H11). 

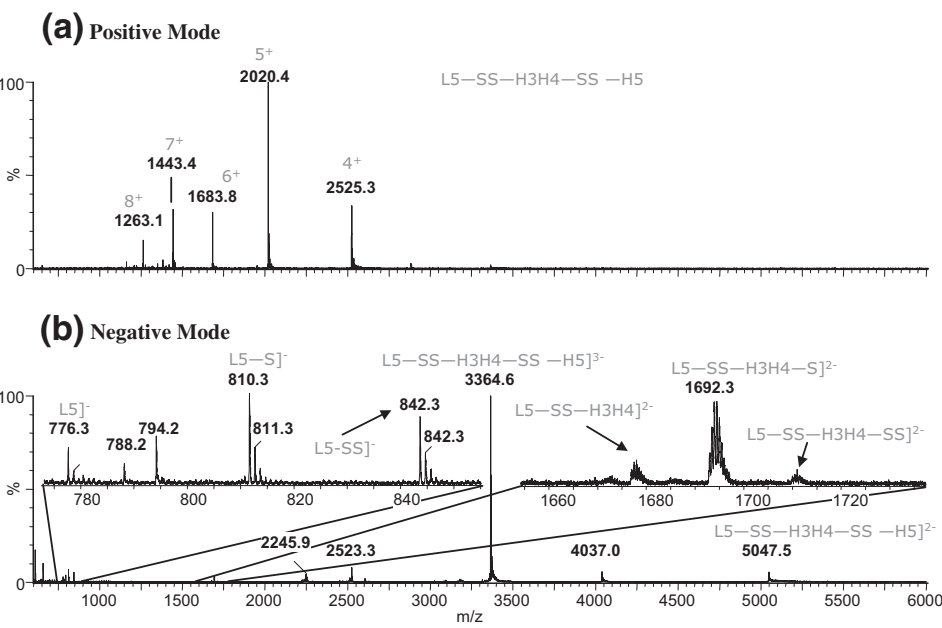

Figure 6. Mass spectra of HPLC peak eluting at 112 min (see Figure 2). (a) positive ESI-TOF, (b) negative ESI-TOF. The HPLC peak was identified as two peptides from the heavy chain and one peptide from the light chain linked via disulfide bonds (L5-SS-H3H4-SS-H5).

mode. The fragment ions were accompanied by the signature ions of \pm sulfur atoms. Similar results were achieved with the ion trap technology (data not shown).

The intact di-peptides $\mathrm{H} 1-\mathrm{SS}-\mathrm{H} 2$ linked via disulfide bond was observed at $\mathrm{m} / \mathrm{z} 2388.6(4+), \mathrm{m} / \mathrm{z}$ $1911.0(5+), m / z 1592.7(6+)$, and $m / z 1365.3(7+)$ in positive ion mode, and at $\mathrm{m} / \mathrm{z} 4774.1(2-)$ and $\mathrm{m} / \mathrm{z}$ 3182.0 (3-) in the negative ion mode (data not shown). In-source fragmentation of the dipeptide in negative ion mode resulted in cleavage at the sulfursulfur bond yielding peptides $\mathrm{H} 1-\mathrm{S}^{2-}(\mathrm{m} / \mathrm{z}$ 2246.1) and $\mathrm{H} 2-\mathrm{S}^{2-}(\mathrm{m} / \mathrm{z}$ 2525.3). The fragment ions were accompanied by the signature ions of \pm sulfur atoms (data not shown).

Finally, Figure 6 shows the ESI-TOF mass spectra of peptides L5-SS-H3H4-SS-H5 linked via two disulfide bonds in the positive (Figure 6a) and negative (Figure $6 \mathrm{~b}$ ) ionization modes. In-source fragmentation of the peptide, represented mainly by ions at $\mathrm{m} / z 5047.5$ $(2-)$ and $m / z 3364.3(3-)$, in negative ion mode resulted in cleavage at the sulfur-sulfur bond yielding peptides

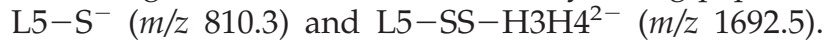
Fragment $\mathrm{L} 5-\mathrm{S}^{-}$was only observed as a single species (only with hydrogen transfer and not without) unlike all other fragments observed before. The fragment ions were accompanied by the signature ions of \pm sulfur atoms. In addition, we observed the formation of a dimer peak at $\mathrm{m} / \mathrm{z} 4037.0$ (5-).

There were no in-source fragments observed for this large ion in the negative ionization mode using the ion trap (data not shown).

Both instruments were limited on the number of disulfides that could be dissociated. The hinge peptide of the heavy chain $C^{6} C^{7} V_{E C}^{8} P^{2} C^{9}$ PAPPVAGPSVFLFPPKPK, which forms a homodimer, presumably via 4 disulfide bonds, could not be fragmented using either instrument. The hinge peptide $\mathrm{H} 6 \mathrm{H} 7 \mathrm{H} 8 \mathrm{H} 9$ was identified based on its unique molecular weight (Table 1) as a dimer linked via four disulfide bonds in the positive and negative ionization mode in both the ion trap and ESI-TOF instruments (data not shown). This dipeptide $C^{6} C^{7} V_{E C}^{8} P^{8} C^{9}$ PAPPVAGPSVFLFPPKPK represents another challenge, which cannot be overcome with the described approach - a possible singly charged fragment ion would have the same $\mathrm{m} / \mathrm{z}$ value compared with the doubly charge precursor ion.

In addition to the expected disulfide-linked peptides, we identified several unexpected, high molecular weight species at retention times 120 to $125 \mathrm{~min}$ (see Figure 2) based on their unique masses. The molecular weight values of those species were measured using the ESI-TOF instrument as $12,775.2 \mathrm{Da}$, 15,453.3 Da, 16,065.9 Da, 16,678.2 Da, 25,551.0 Da, 26,164.5 $\mathrm{Da}$, and 26,778.0 $\mathrm{Da}$, matching the theoretical molecular weight of peptides 12,773.6 Da: L5 + H3H4 $+\mathrm{H} 5+\mathrm{H} 6 \mathrm{H} 7 \mathrm{H} 8 \mathrm{H} 9,15,450.9$ Da: $\mathrm{L} 5+\mathrm{H} 3 \mathrm{H} 4+\mathrm{H} 5+$ $2 \times$ H6H7H8H9, 16,064.6 Da: L5 + H3H4 + H5 + $2 \times$ H6H7H8H9 + 613.7, 16,678.3 Da: L5 + H3H4 + H5 + $2 \times$ H6H7H8H9 + $2 \times 613.7,25,547.2$ Da: $2 \times($ L5 + $\mathrm{H} 3 \mathrm{H} 4+\mathrm{H} 5)+2 \times$ H6H7H8H9, 26,160.9 Da: $2 \times$ $(\mathrm{L} 5+\mathrm{H} 3 \mathrm{H} 4+\mathrm{H} 5)+2 \times \mathrm{H} 6 \mathrm{H} 7 \mathrm{H} 8 \mathrm{H} 9+613.7$, and 26,774.6 Da: $2 \times(\mathrm{L} 5+\mathrm{H} 3 \mathrm{H} 4+\mathrm{H} 5)+2 \times$ H6H7H8H9 $+2 \times 613.7$, respectively linked via disulfide bonds, indicating the presence of unexpected disulfide linkages involving the hinge peptide $C^{6} C^{7}$ VEC ${ }^{8}$ PPC ${ }^{9}$ PAPPVAGPSVFLFPPKPK. The addition of 613.7 resulted from a missed cleavage at the $\mathrm{N}$-terminus of the hinge peptide $\mathrm{H} 6 \mathrm{H} 7 \mathrm{H} 8 \mathrm{H} 9$ and the addition of amino acids TVERK (molecular weight of peptide is $631.7-\mathrm{H}_{2} \mathrm{O}=613.7$ ). At this time, we do not know the exact disulfide linkages of those peptides, which will be the focus of future studies. However, the use of negative ionization did not result in fragmentation of these large $(>10 \mathrm{kDa})$ disulfidelinked peptides, again, indicating a limitation for solving the disulfide structure of large peptides. 
The data presented in this paper indicate that the size of the disulfide-linked peptides is inversely related to the efficiency of the fragmentation. This phenomenon was expected and is probably similar to fragmentation using other techniques like collision-induced dissociation. Bure et al. showed for five synthetic peptide thioesters of increasing length that the fragmentation efficiency is higher for the smallest peptides than for the longest under in-source and in-collision cell fragmentation, using an electrospray source coupled to a triple quadrupole [17].

Nondisulfide containing peptides could be identified using positive ion tandem mass spectra and several commercially available fully automated software programs. However, none of the disulfide-containing peptides in this study could be identified with this approach because the MS/MS data from disulfidecontaining peptides are typically poor and the software cannot recognize these peptides. Therefore, manual identification of the disulfide-containing peptides was used, relying on the observed molecular weights from the mass spectra and the theoretically calculated masses of the disulfide-linked peptides. This approach is useful as long as the disulfide connectivity is already known or if only very few peptides contain cysteine residues. However, if many peptides contain cysteine residues and if more than two peptides are connected via disulfide bonds, it becomes difficult to determine the connectivity because of the large number of different combinations that are possible. In such a case, where several possible combinations of peptides result in the same molecular weight, the full mass spectra from the negative ionization mode analysis could be used for the identification of the disulfide-containing peptides.

\section{Conclusions}

We described a method for the identification of disulfidecontaining peptides using nonreduced peptide maps and mass spectral analysis by reversed-phase liquid chromatography in-line with negative electrospray ionization mass spectrometry. Analysis of disulfide-containing peptides in negative ionization mode resulted in specific fragmentation at the sulfur bonds. The fragmentation information could be used for identification of those disulfide-containing peptides. We optimized previously reported methods to allow in-line analysis with HPLC separation making it amenable to high throughput applications. Two techniques (ion trap and ESI-TOF) were evaluated for in-source fragmentation efficiency, showing that the ion trap resulted in more complete fragmentation for selected peptides. However, the limited mass range and the low mass accuracy of the ion trap technology are clear disadvantages of this technique compared with the ESI-TOF instrument used in this study. Both instruments were limited in the number of disulfides that could be simultaneously fragmented, e.g., the hinge peptide $C^{6} C^{7} V_{E C}^{8}{ }^{8} C^{9}$ PAPPVAGPSVFLFPPKPK linked via four disulfide bonds could not be fragmented with either instrument. We also observed a reverse dependency of the molecular weight and the fragmentation efficiency for both instruments.

\section{Acknowledgments}

The authors thank Ming Li, Jette Wypych, Szilian Fodor, Yaoqing Liu, Greg Flynn, and Tom Dillon for originally developing the nonreduced Lyc-C peptide map used in this report with very few modifications, and the initial identification of the unexpected disulfide linkages. They thank Zhongqi Zhang (Amgen Inc. Process Development) for the development of a software tool allowing the assignment of disulfide-linked peptides based on the theoretical mass of enzymatic peptides. They also thank Professor Roman Zubarev for fruitful discussions.

\section{References}

1. Mhatre, R.; Woodard J.; Zeng, C. Strategies for Locating Disulfide Bonds in a Monoclonal Antibody Via Mass Spectrometry. Rapid Commun. Mass Spectrom. 1999, 13, 2503-2510.

2. Zhang, W.; Marzilli, L. A.; Rouse J. C.; Czupryn, M. J. Complete Disulfide Bond Assignment of a Recombinant Immunoglobulin G4 Monoclonal Antibody. Anal. Biochem. 2002, 311, 1-9.

3. Yen, T. Y.; Yan, H.; Macher, B. A. Characterizing Closely Spaced, Complex Disulfide Bond Patterns in Peptides and Proteins by Liquid Chromatography/Electrospray Ionization Tandem Mass Spectrometry. J. Mass Spectrom. 2002, 37, 15-30.

4. Stults, J. T.; Bourell, J. H.; Canova-Davis, E.; Ling, V. T.; Laramee, G. R.; Winslow, J. W.; Griffin, P. R.; Rinderknecht, E.; Vandlen, R. L. Structural Characterization by Mass Spectrometry of Native and Recombinant Human Relaxin. Biomed. Environ. Mass Spectrom. 1990, 19, 655-664.

5. Bean, M. F.; Carr, S. A. Characterization of Disulfide Bond Position in Proteins and Sequence Analysis of Cystine-Bridged Peptides by Tandem Mass Spectrometry. Anal. Biochem. 1992, 201, 216-226.

6. Jones, M. D.; Hunt, J.; Liu, J. L.; Patterson, S. D.; Kohno, T.; Lu., H. S. Determination of Tumor Necrosis Factor Binding Protein Disulfide Structure: Deviation of the Fourth Domain Structure from the TNFR/ NGFR Family Cysteine-Rich Region Signature. Biochemistry 1997, 36, 14914-14923.

7. Patterson S. D.; Katta, V. Prompt Fragmentation of Disulfide-Linked Peptides During Matrix-Assisted Laser Desorption Ionization Mass Spectrometry. Anal. Chem. 1994, 66, 3727-3732.

8. Gorman, J. J.; Ferguson, B. L.; Nguyen, T. B. Use of 2,6-Dihydroxyacetophenone for Analysis of Fragile Peptides, Disulphide Bonding, and Small Proteins by Matrix-Assisted Laser Desorption/Ionization. Rapid Commun. Mass Spectrom. 1996, 10, 529-536.

9. Qin, J.; Chait, B. T. Identification and Characterization of Posttranslational Modifications of Proteins by MALDI Ion Trap Mass Spectrometry. Anal. Chem. 1997, 69, 4002-4009.

10. Rubino, F. M.; Verduci, C.; Giampiccolo, R.; Pulvirenti, S.; Brambilla, G.; Colombi, A. Characterization of the Disulfides of Biothiols by Electrospray Ionization and Triple-Quadrupole Tandem Mass Spectrometry. J. Mass Spectrom. 2004, 39, 1408-1416.

11. Parker, C. E.; de Wit, J. S.; Smith, R. W.; Gopinathan, M. B.; Hernandez, O.; Tomer, K. B.; Vestal, C. H.; Sanders, J. M.; Bend, J. R. Analysis of Glutathione Conjugates and Related Compounds by Thermospray Mass Spectrometry. Biomed. Environ. Mass Spectrom. 1988, 15, 623-633.

12. Chrisman, P. A.; McLuckey, S. A. Dissociations of Disulfide-Linked Gaseous Polypeptide/Protein Anions: Ion Chemistry with Implications for Protein Identification and Characterization. J. Proteome Res. 2002, 1, 549-557.

13. Bramwell, G. J.; Depetalta, G. U.; Eng, M. L.; Truong, L. K.; Ling, V. T. Negative Ion Mode LC MS/MS: A Potential High Throughput Method for Determining Disulfide Linkages on Proteins. Proceedings of the 52nd ASMS Conference; Nashville, TN, June 2004.

14. Zhang, Z. Prediction of Low-Energy Collision-Induced Dissociation Spectra of Peptides. Anal. Chem. 2004, 76, 3908-3922.

15. Zhang, Z. De Novo Peptide Sequencing Based on a Divide-andConquer Algorithm and Peptide Tandem Spectrum Simulation. Anal. Chem. 2004, 76, 6374-6383.

16. Zubarev, R. A.; Kruger, N. A.; Fridriksson, E. K.; Lewis, M. A.; Horn, D. M.; Carpenter, B. K.; McLafferty, F. W. Electron Capture Dissociation of Gaseous Multiply-Charged Proteins is Favored at Disulfide Bonds and Other Sites of High Hydrogen Atom Affinity. J. Am. Chem. Soc. 1999, 121, 2857-2862.

17. Bure, C.; Boujard, O.; Bertrand, M.; Lange, C.; Delmas, A. F. Letter: Collision-Induced Dissociation of Peptide Thioesters: Influence of the Peptide Length on the Fragmentation. Eur. J. Mass Spectrom. 2005, 11, 31-34. 